NASA Technical Memorandum 105596

AIAA-92-3384

P.10

\title{
Slush Hydrogen Transfer Studies at the NASA K-Site Test Facility
}

Terry L. Hardy and Margaret V. Whalen

Lewis Research Center

Cleveland, Ohio

Prepared for the

28th Joint Propulsion Conference and Exhibit cosponsored by AIAA, SAE, ASME, and ASEE

Nashville, Tennessee, July 6-8, 1992

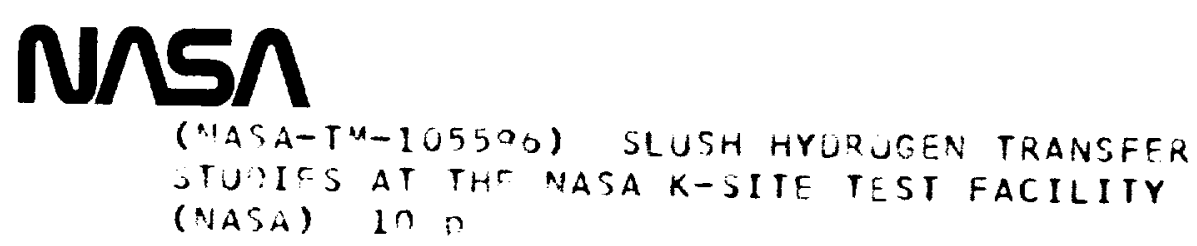


surface of the fluid, the pressure in the generator was allowed to increase a few torr, providing the thaw which allowed the solids to sink into the liquid. One freeze and thaw was referred to as a cycle, and repeated cycling accumulated solids. This cycling process (freezing and thawing) around the triple point was repeated until the solid fraction reached a desired level. The change in pressure from the freeze through the thaw portion of the cycle could be increased through the addition of gaseous helium or hydrogen to the generator ullage.

A propeller-type mixer was used during the production process to help break up the solid layer on the surface and to keep the slush hydrogen homogeneous. This mixer was operated from 0 to 60 percent of the maximum $400 \mathrm{rpm}$ speed. The mixer had the capability of being operated such that the fluid could be pushed in the upward or downward direction. The density of the slush hydrogen in the generator was measured using an externally mounted nuclear radiation attenuation (NRA) densimeter with a 150 -millicurie ( $\mathrm{mCi}$ ) cesium 137 source. The generator was also instrumented with a capacitance liquid level probe and silicon diode temperature sensors. In addition, the generator had a viewing port to allow visual access to the generator during slush hydrogen production.

Following production, the slush hydrogen was transferred through the flow system to a 5 -ft diameter spherical test tank located inside the K-Site 25 - $\mathrm{ft}$-diameter vacuum chamber. The flow system itself was approximately $125 \mathrm{ft}$ long and constructed of $1.5 \mathrm{in}$. Schedule 5 stainless steel vacuum-jacketed pipe to the chamber wall. Inside the vacuum chamber 1.5 in. bare stainless steel pipe was used, and the facility vacuum (approximately $1 \times 10^{-6}$ torr) provided the insulation for the line. The transfer system consisted of five valves and various elbows, mitre bends, bayonet fittings, bellows, and flex lines. The transfer line was equipped with a pressure tap and transducer located at the outlet of the generator to give an upstream pressure measurement. The transfer line was also equipped with an NRA densimeter with a $25-\mathrm{mCi}$ cesium 137 source. The flow line densimeter was horizontally mounted on the transfer line, approximately $9 \mathrm{ft}$ from the tank inlet, to provide a density measurement during transfer for determining slush solid loss. This densimeter had an accuracy of \pm 1 percent, as provided by the manufacturer. The test tank was equipped with a capacitance liquid level sensor and a viewing port for visual access. The liquid level sensor had a manufacturers's reported accuracy of \pm 0.25 in. The test tank also had a mechanical mixer installed in it for use during expulsion experiments. In order to minimize the potential for pressure collapse in the test tank during transfer, this mixer was not used during the transfer process into the tank.

Prior to SLH2 transfer the spherical test tank and flow system were precooled by filling the test tank with normal boiling point liquid hydrogen, then outflowing the liquid through the transfer line back to the supply dewar. Once the liquid had been drained from the test tank through the flow system (a tee in the transfer line allowed for cooling up to the generator, as indicated in Fig. 1), transfer of slush could begin. For most runs the generator mixer was operated at 50 to 60 percent of the maximum $400 \mathrm{rpm}$ speed in the downward direction at the initiation of transfer. During transfer the slush generator was pressurized to a desired level using gaseous helium, the test tank was vented to atmospheric pressure, and slush hydrogen was allowed to flow up to the test tank, initially bypassing the test tank. Once it was clear that slush hydrogen existed in the transfer line, as indicated by the densimeter on the line near the test tank inlet, the test tank valve was opened and slush hydrogen was transferred into the tank.
Generally, the generator pressure was set at 35 psia or higher, based on results of previous experiments. ${ }^{4}$ If a lower upstream transfer pressure was desired, the generator pressure was decreased once slush hydrogen started nowing into the test tank. The triple point liquid hydrogen runs were performed in the same manner as the slush hydrogen runs except that, for some runs, the generator mixer was not used. In the normal boiling point hydrogen transfers there was no mixing in the generator. In addition, the bypass to the test tank was not used for the triple point and normal boiling point liquid hydrogen runs.

Pressure drop information for the transfer of slush was obtained using the pressure sensor in the line near the generator outlet (upstream line pressure) and the pressure measurement for the spherical test tank. The flow rate was obtained by measuring the change in liquid level in the test tank and calculating the average volumetric flow rate based on flow time. To assure that a steady-state measurement was obtained, the calculation used only the change in liquid level from approximately 10 to 40 in. in the tank. The accuracy of calculating flow rate in this method was approximately $\$ 2$ percent, based on the accuracy of the liquid level measurement. The density measurements reported represent the average density during the first $20 \mathrm{sec}$ of the steady-state flow time for both the line and generator densimeters. The density values at the beginning of the run were chosen for the solid loss determinations as the densities at the start of the run were thought to be representative of the solid fraction loss during flow. At later periods in the run, particularly near the end of the run, the measurement of the slush solid fraction in the generator dropped off dramatically for many cases. This was the result of a generator liquid level dropping below the generator densimeter sampling level. It should be noted that using a higher number of points to obtain an average solid fraction loss would not change the general results obtained using the density data. All transfer data were obtained using the ESCORT data recording system at a nominal rate of one scan of data every 5 sec.

\section{Analytical Model}

FLUSH, the analytical model used to calculate pressure drop and solid loss in slush hydrogen flow systems, was used for comparison against the experimental results. FLUSH solves the one-dimensional, steady-state energy equation and the Bernoulli equation to provide these estimates. ${ }^{6}$ Input to the FLUSH code included element length and diameter, fluid temperature, heat leak into each element, flow resistance coefficient, pipe roughness, initial upstream pressure, initial slush hydrogen solid fraction, and range of volumetric flow rates being considered. The values of heat leak for all elements and flow resistance coefficients for the valves were obtained from the manufacturer's data. The values of the flow resistance coefficient for the mitre bends and elbows were obtained from standard correlations in the literature. ${ }^{7}$ The pipe roughness was also obtained from manufacturer data. Output from the FLUSH code included pressure drop, final solid fraction at the end of the flow system, final liquid temperature, and mass flow rate.

\section{$\underline{\text { Results }}$}

\section{Production}

Production of slush hydrogen was achieved through the freeze-thaw process, as described above. All production tests described here were conducted using a freeze-thaw cycle time similar to that used in previous tests. ${ }^{4}$ Seventy-five batches of 
slush hydrogen were produced in Test Series II, with an average batch size of $640 \mathrm{gal}$. The total amount of slush hydrogen produced during this test series was approximately 48000 gal. The solid fraction of the slush hydrogen batches ranged from 53 to 63 percent $\left(5.12\right.$ to $\left.5.18 \mathrm{lb} / \mathrm{ft}^{3}\right)$. The freeze-thaw time for production of a 50-percent solid fraction or greater batch of slush hydrogen was approximately 1.5 to $3 \mathrm{hr}$ in Test Series II. This time does not include the time to reach triple point conditions starting from normal boiling point liquid hydrogen.

\section{Flow Stagnation During Transfer}

From previous testing ${ }^{4}$ it was determined that flow stagnation (the inability to transfer slush hydrogen from the generator to the test tank) could be prevented by using a high upstream pressure ( 30 psia or greater) and by operating the mixer in a downward direction at 50 to 60 percent maximum speed to prevent agglomeration of solids in the bottom of the generator. When these techniques were used no flow stagnation occurred in the Test Series II experiments. However, several tests were performed to determine the minimum mixer speed required to prevent flow stagnation. Three separate attempts were made at transferring slush hydrogen using a mixer speed of 40 percent. In two tests, each at an approximate slush hydrogen volume of $675 \mathrm{gal}$, no transfer was possible at $\mathbf{4 0}$ percent mixer speed. Once the mixer speed was increased to 60 percent, flow was initiated in these experiments. In the third test, at a slush hydrogen volume of $550 \mathrm{gal}$ a mixer speed of $\mathbf{4 0}$ percent was sufficient to transfer slush hydrogen to the test tank without stagnation. It appears that the volume of the slush hydrogen in the generator may affect the ability to transfer slush hydrogen in this system. At the higher slush hydrogen volumes, more solids exist in the generator than is the case at lower volumes. These solids may collect in the bottom of the generator, possibly leading to stagnation when mixer speeds less than 50 percent are used. Therefore, mixing appears to affect the ability to transfer slush hydrogen. This result could apply to flight support tanks with large quantities of slush hydrogen; in these tanks mixing may significantly affect the ability to transfer the fluid.

\section{Flow Rate Versus Pressure Drop: SLH2, TPH2, and NBPH2}

Figure 4 shows the volumetric flow rate versus pressure drop data for slush hydrogen, triple point hydrogen, and normal boiling point liquid hydrogen transfer through the K-Site flow system. The slush hydrogen and triple point hydrogen data were obtained in Test Series II, while the normal boiling point liquid hydrogen data were from Test Series I. The data in Fig. 4 indicate that slush hydrogen, triple point liquid hydrogen, and normal boiling point liquid hydrogen display similar volumetric flow rate characteristics. Calculations performed comparing the flow characteristics of the three fluids show that as density increases the volumetric flow rate should decrease. It appears from the figure that the normal boiling point volumetric flow rate is actually lower than that for either the slush hydrogen or triple point hydrogen; however, this difference in volumetric flow rate was small.

Figure 5 shows the mass flow rate versus pressure drop. The mass flow rate was obtained from the volumetric flow rate and the line density (an average of the entire run). It can be seen in the figure that the mass flow rate for slush hydrogen is slightly higher than the triple point runs at the same pressure drop. The normal boiling point data show the lowest mass flow rate when compared with the other fluids. Because mass flow rate is proportional to volumetric flow rate and density, slush hydrogen should show a slightly higher mass flow rate when compared to normal boiling point liquid or triple point hydrogen at the same pressure drop, as was the case shown in Fig. 5. More accurate means of determining flow rates for slush hydrogen are required if further comparison between liquid hydrogen and slush hydrogen transfer is made, as the differences in the transfer characteristics of the three fluids appear to be small.

The flow characteristics discussed above were determined based on average pressures in the slush generator and the test tank during the transfer process. Examination of the data indicated that the variation of pressure in the slush generator was small (less than 0.5 psia) during the transfer process. The test tank pressure, however, was found to change by a larger amount during the transfer process. The average pressure change in the test tank was 0.7 psia. Because the pressure drop is an average for the run, this tank pressure increase could present some inaccuracy in the flow characteristic determination, leading to the scatter in the slush hydrogen data shown in Figs. 4 and 5. The tank pressure also changed for the triple point and normal boiling point hydrogen transfers; however, the change in pressure was not as great, averaging 0.1 psia for both fluids. This reduced pressure change may have led to less scatter in the triple point and normal boiling point results shown in Figs. 4 and 5.

The comparisons of the flow rate-pressure drop chararteristics show that the flow rates of slush hydrogen, triple point hydrogen, and normal boiling hydrogen were similar. This result implies that, in terms of steady-state flow characteristics, slush hydrogen transfer systems can be designed using liquid hydrogen technology.

\section{Flow Rate Versus Pressure Drop: FLUSH Analytical Com- parisons}

Figure 6 shows the comparison of the analytical results with the slush hydrogen experimental data for volumetric flow rate versus pressure drop. The data show that FLUSH provided close agreement in predicting the pressure drop/flow rate characteristics for slush bydrogen, although the code appears to underpredict the pressure drop for most runs. This agreement was within 11 percent (total) in all cases shown here. Similar results are provided for triple point hydrogen and normal boiling point liquid hydrogen in Figs. 7 and 8 , respectively. The FLUSH code gave similar agreement with the triple point data, within 10 percent on volumetric flow rates greater than $100 \mathrm{gpm}$, within 16 percent at flow rates less than $100 \mathrm{gpm}$. The agreement for all normal boiling point liquid hydrogen runs was within 18 percent for most cases above $100 \mathrm{gpm}$, and within 35 percent for most cases below $100 \mathrm{gpm}$, but the pressure drop was overpredicted for all cases.

The close agreement between FLUSH and the experimental data was expected as standard liquid friction factor correlations were used, and, from the data shown in Figs. 4 and 5 , slush hydrogen showed similar flow characteristics when compared to normal boiling point liquid hydrogen. Differences between the code and the experimental data may have been the result of inaccuracies in determining flow rate, as discussed above, as well as some potential inaccuracies in defining the piping system, such as pipe roughness. In addition, only steady-state flow is being considered here; transient flow behavior must still be examined. However, it appears from the data presented here that steady-state slush hydrogen flow characteristics can be modeled accurately for large flow systems using the FLUSH code. 


\section{Slush Hydrogen Solid Fraction Losses}

Figure 9 shows the absolute solid fraction loss during transfer, defined as the solid fraction in the generator minus the solid fraction in the flow line entering the test tank. This solid fraction loss is compared to predictions with the FLUSH code. As discussed above, the density and solid fraction values are an average of the data in the first $20 \mathrm{sec}$ of the transfer process. As shown in the figure, the losses were less than 15 percent $(0.15)$ for most runs. However, the data scatter was quite large, ranging from 0 to 17 percent $(0$ to 0.17 ). Although the FLUSH predictions shown in Fig. 9 fall in the middle of the solid fraction loss data, the scatter on the data precludes verification of the thermodynamic models within the FLUSH code.

Examination of transient density data showed that there were many cases in which the flow line densimeter actually gave values which were higher than the generator densimeter readings, some by as much as $0.06 \mathrm{lb} / \mathrm{ft}^{3}$. These points were not included in Fig. 9 as this implies a negative solid fraction loss, or solid fraction gain, during transfer, which is physically impossible. Figure 10 shows the transient density measurements during the transfer process for a typical slush hydrogen transfer run. In the figure, run number (RUN NO.) was the test number assigned by the researcher, while reading number (RDG NO.) refers to the number assigned to each test run by the data recording system. As can be seen in Fig. 10, the flow line density measurements varied greatly (by $0.05 \mathrm{lb} / \mathrm{ft}^{3}$ ) during the transfer period, while the slush hydrogen generator density remained nearly constant. In previous tests ${ }^{4}$ it was postulated that wide variations in density and negative solid losses during transfer were indicative of nonequilibrium flow behavior at low transfer rates (less than $100 \mathrm{gpm}$ ). It appears from the current data that wide variations in the transfer density measurements may occur even at higher flow rates. It is not clear at this time whether this variation is the result of a physical phenomenon, such as solids settling during transfer, or whether these results point to an inherent difficulty in measuring density during the flow process. Future multidimensional modeling efforts may indicate whether solid stratification could occur at these flow rates in this slush hydrogen transfer system.

In the existing transfer system a nuclear radiation attenuation densimeter was used to obtain the flow line density data. In future systems it may be desirable to examine the use of other types of densimeters for this measurement. Another technique to obtain density change during transfer would be the measurement of density in a receiver tank, assuring that the slush hydrogen is well-mixed in this tank. Given the density results obtained here it is clear further work is necessary to determine solid fraction loss in a slush hydrogen transfer system.

\section{Concluding Remarks}

Experiments were conducted at the NASA Plum Brook K-Site Facility to examine slush hydrogen transfer characteristics. Flow rate-pressure drop characteristics were obtained during transfer from a slush hydrogen generator vessel to a 5-ft-diameter spherical test tank for slush hydrogen, triple point hydrogen, and normal boiling point liquid hydrogen. These characteristics were used for comparison against the FLUSH analytical code, a one-dimensional model developed at
NASA Lewis for calculating pressure drop and solid fraction loss during the flow of slush hydrogen.

Transfer tests indicate that flow stagnation can occur at lower generator mixer speeds, possibly because of increased agglomeration of solids in the bottom of the generator with low mixer speeds. No flow stagnation occurred at the higher mixer speeds. The flow data indicated that slush hydrogen, triple point hydrogen, and normal boiling point liquid hydrogen exhibited similar volumetric and mass flow rate-pressure drop characteristics, indicating that the fluids flowed essentially the same. Density measurements showed slush hydrogen solid fraction losses of less than 15 percent for most cases. However, wide variations in the density loss data and the transient flow line density measurements point toward the need for further study in the area of slush hydrogen density measurements in flow systems.

Finally, the FLUSH code gave agreement to within 11 percent for the slush hydrogen flow characteristics. For the triple point transfer tests the difference between FLUSH and the flow data was within 16 percent for all cases. For normal boiling point liquid hydrogen runs this agreement was within 18 percent at high flow rates, and within 35 percent at flow rates of less than $100 \mathrm{gpm}$. The large scatter on the solid fraction loss data precluded accurate comparisons between the density data and FLUSH analytical predictions.

The test results indicate that slush hydrogen can be transferred through complex flow systems designed for liquid hydrogen. In addition, the technology information obtained in this effort increases the confidence that slush hydrogen or triple point liquid hydrogen can be used on future space vehicles.

\section{$\underline{\text { References }}$}

1. Hannum, N.P., “Technology Issues Associated with Fueling the National Aerospace Plane with Slush Hydrogen," NASA TM-101386, 1989.

2. Kandebo, S.W., "NASP Team Narrows Its Options As First Design Cycle Nears Completion," Aviation Week \& Space Technology, Vol. 134, No. 13, April 1, 1991, p. 80.

3. Friedlander, A., Zubrin, R., and Hardy, T.L., "Benefits of Slush Hydrogen for Space Missions,” NASA TM-104503, 1991.

4. Hardy, T.L., and Whalen, M.V., "Slush Hydrogen Propellant Production, Transfer and Expulsion Studies at the NASA K-Site Facility," NASA TM-105191, 1991. (Also, AIAA Paper 91-3550, 1991.)

5. Whalen, M.V., and Hardy, T.L., "Slush Hydrogen Pressurized Expulsion Studies at the NASA K-Site Facilities." (Also AIAA-Paper-92-3385, 1992.)

6. Hardy, T.L., "FLUSH: A Tool for the Design of Slush Hydrogen Flow Systems," NASA TM-102467, 1990.

7. Flow of Fluids through Valves, Fittings, and Pipe, Crane Co., Hydro-Aire Division, Chicago, IL, TP-410, 1965. 


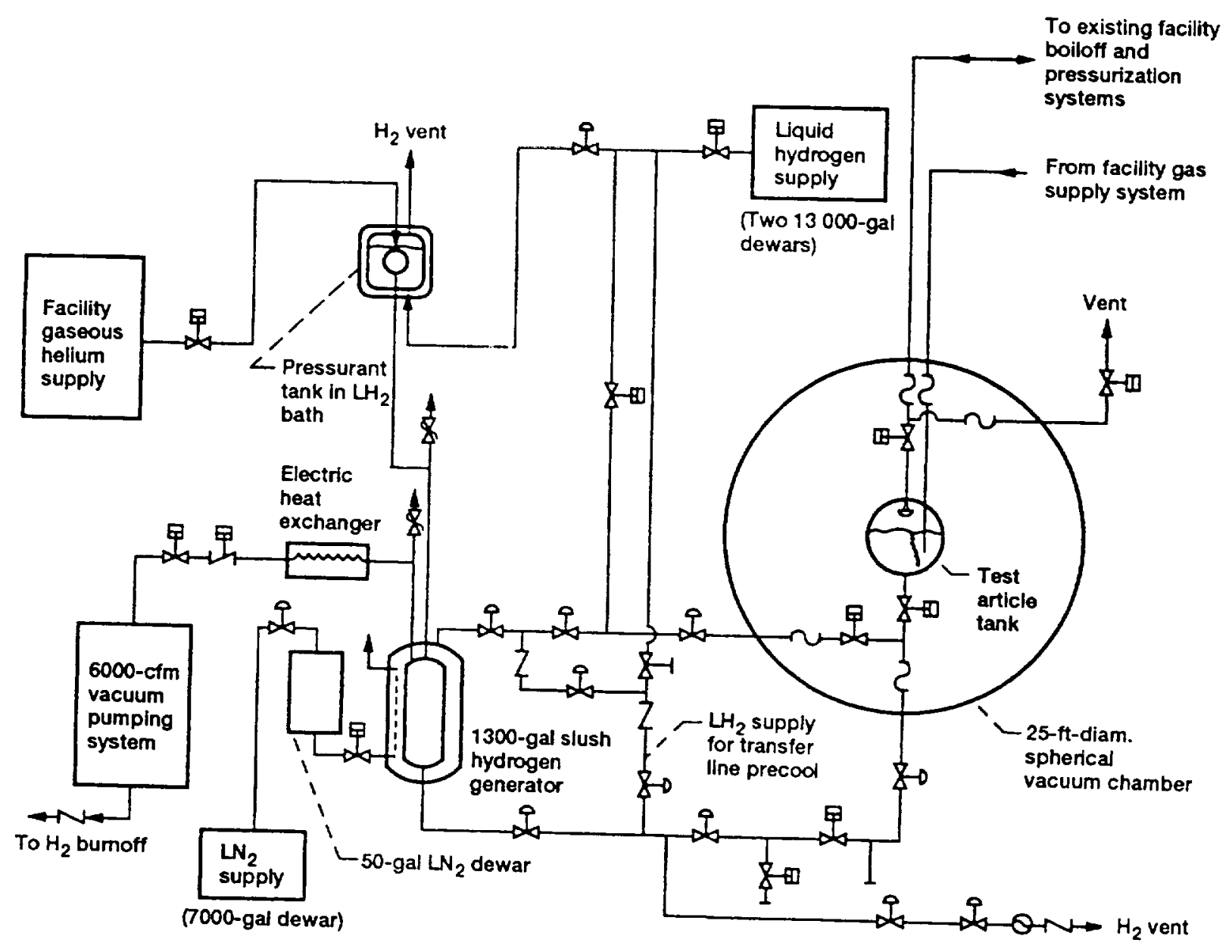

Figure 1.-NASA Plum Brook K-Site Facility schematic.

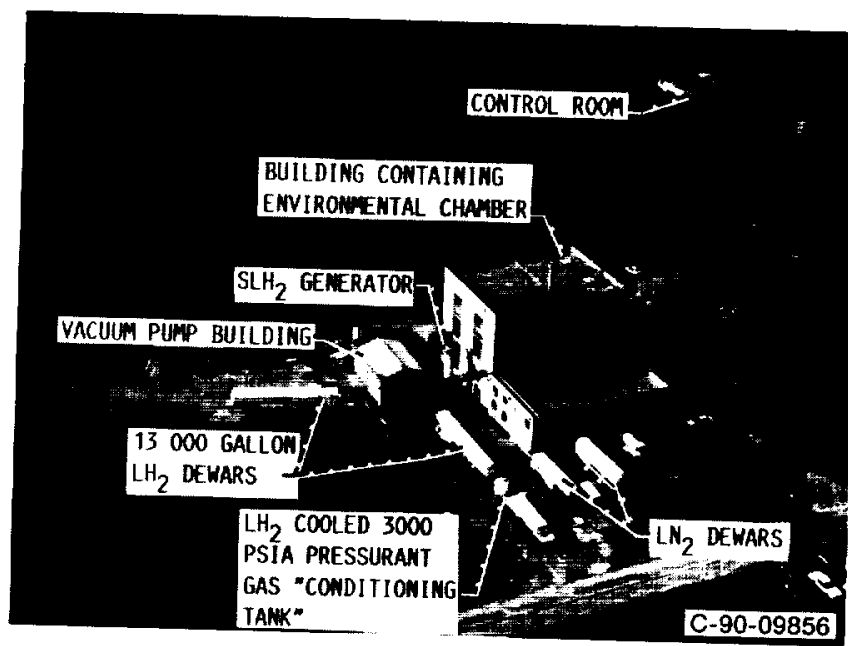

Figure 2.-Overall photograph of NASA Plum Erook K-Site Facility. 


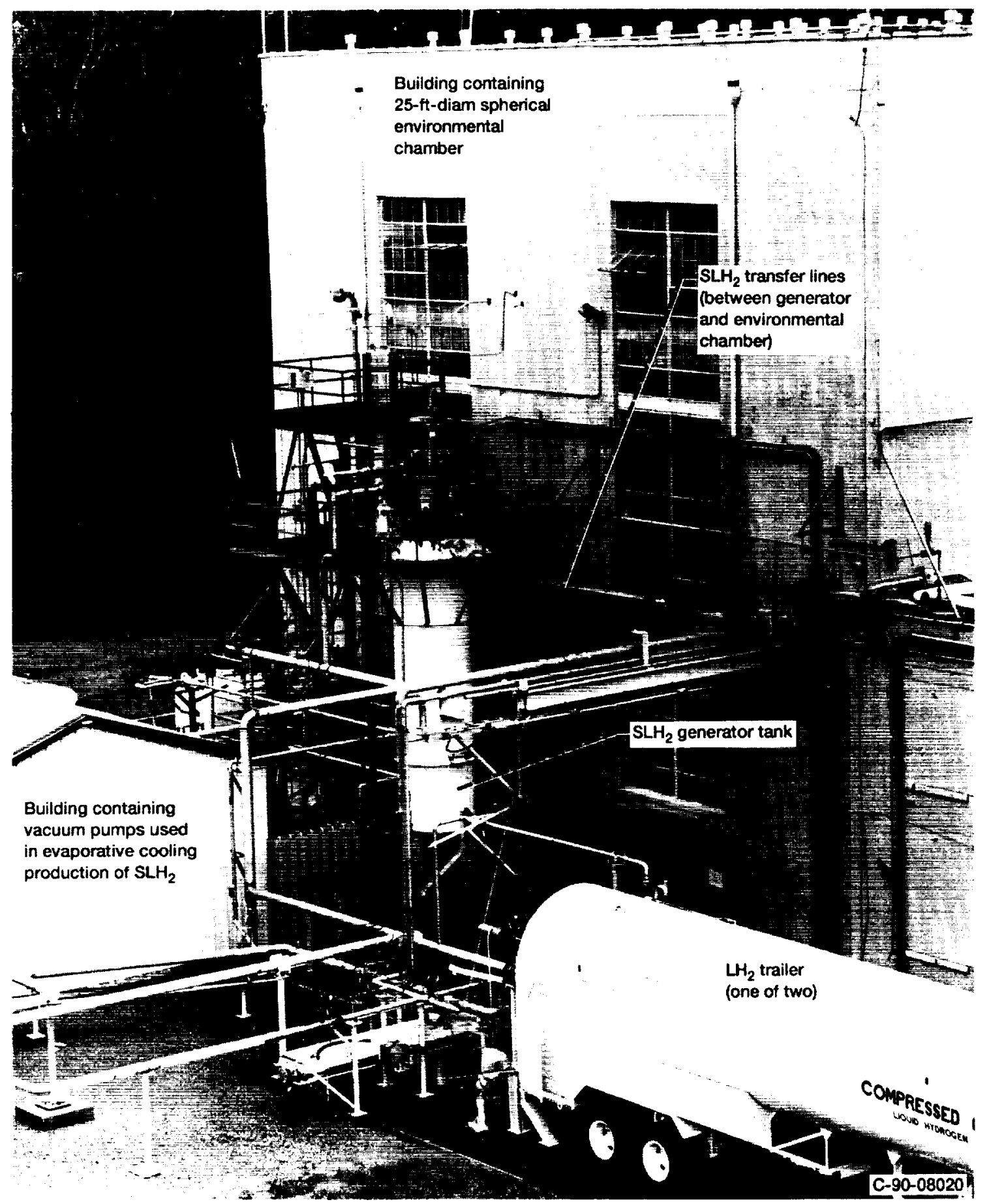

Figure 3.-NASA LeRC SLH ${ }_{2}$ production subsystem at Plum Brook Station. 


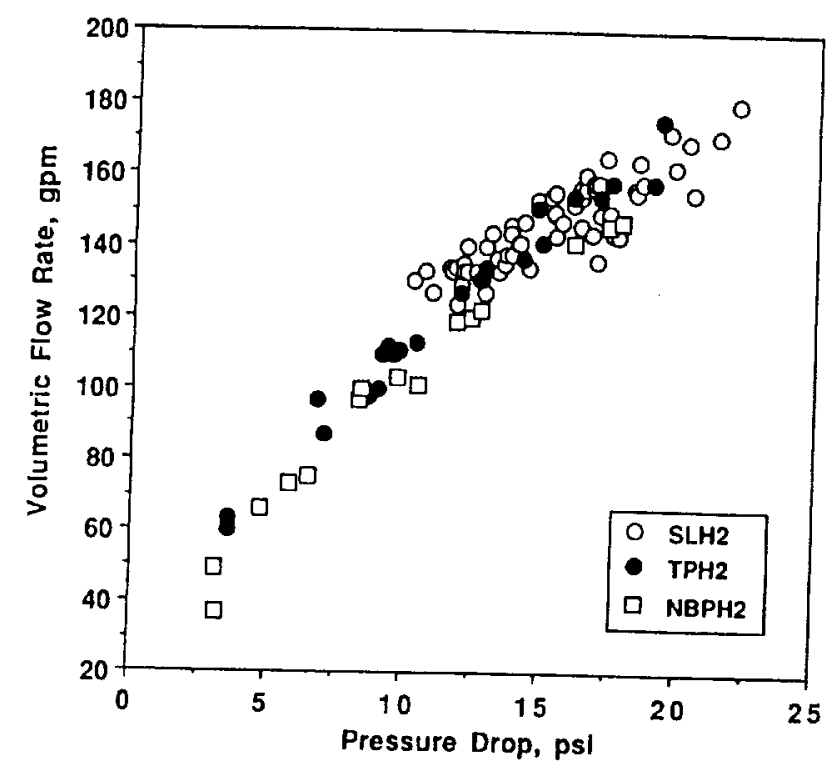

Figure 4.- Volumetric flow rate for slush hydrogen, triple point hydrogen and normal boillng point hydrogen.

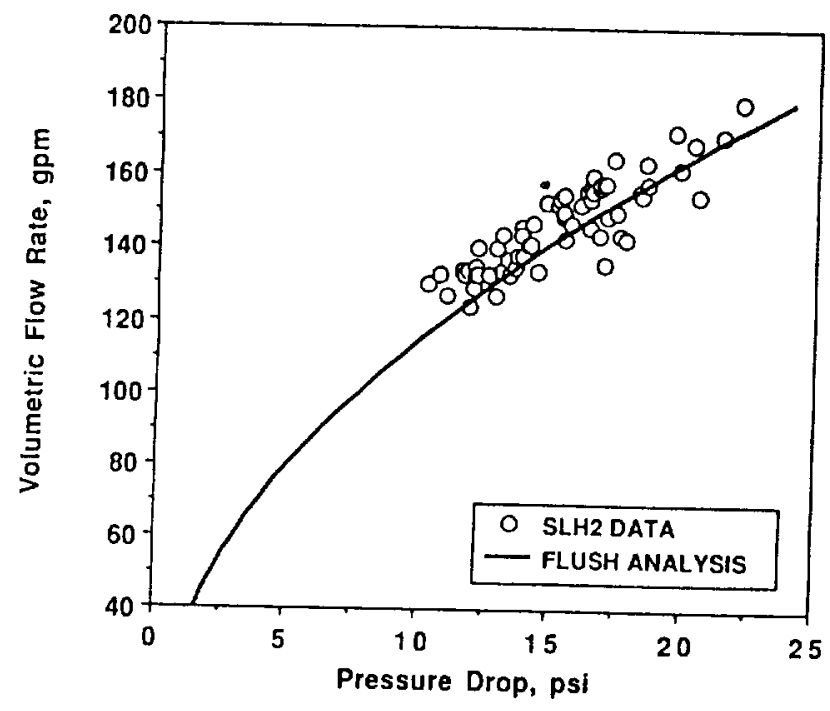

Figure 6.-Comparison of $\mathrm{SLH}_{2}$ volumetrlc flow rate data with FLUSH analysis.

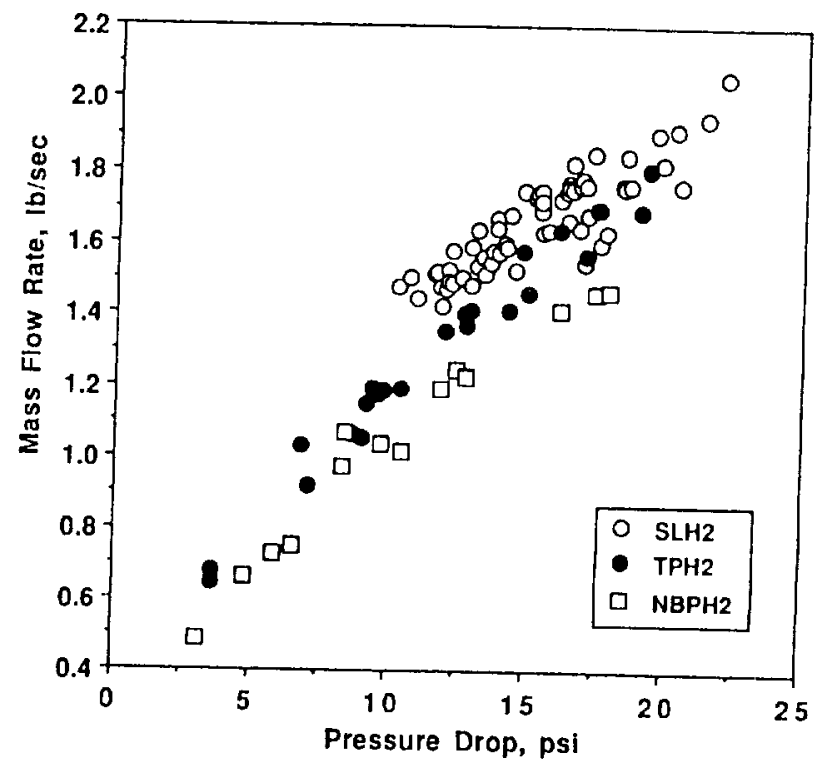

Figure 5.-Mass flow rate for slush hydrogen, triple point hydrogen, and normal boiling point hydrogen.

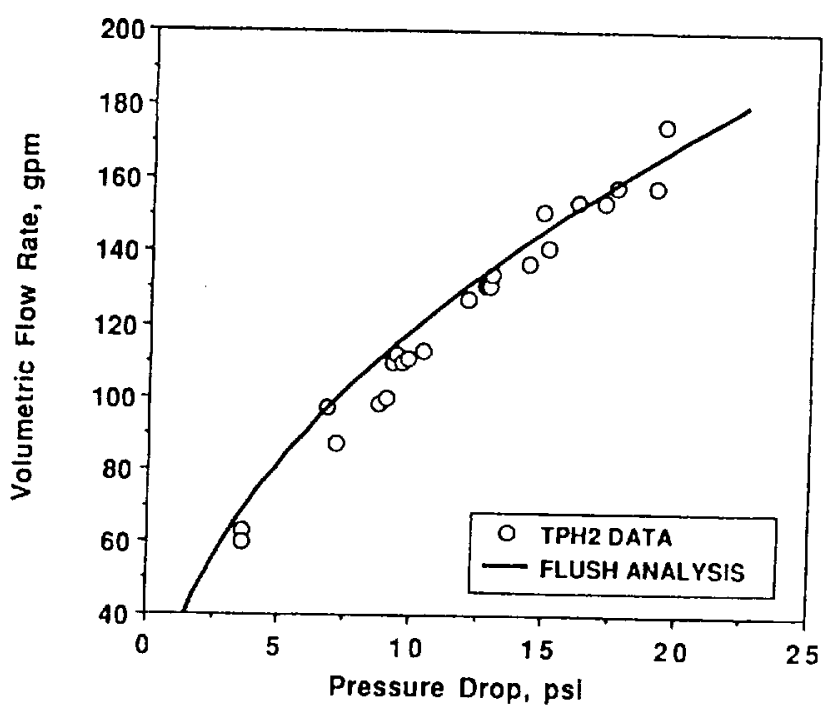

Figure 7.-Comparison of $\mathrm{TPH}_{2}$ volumetric flow rate data with FLUSH analysis. 


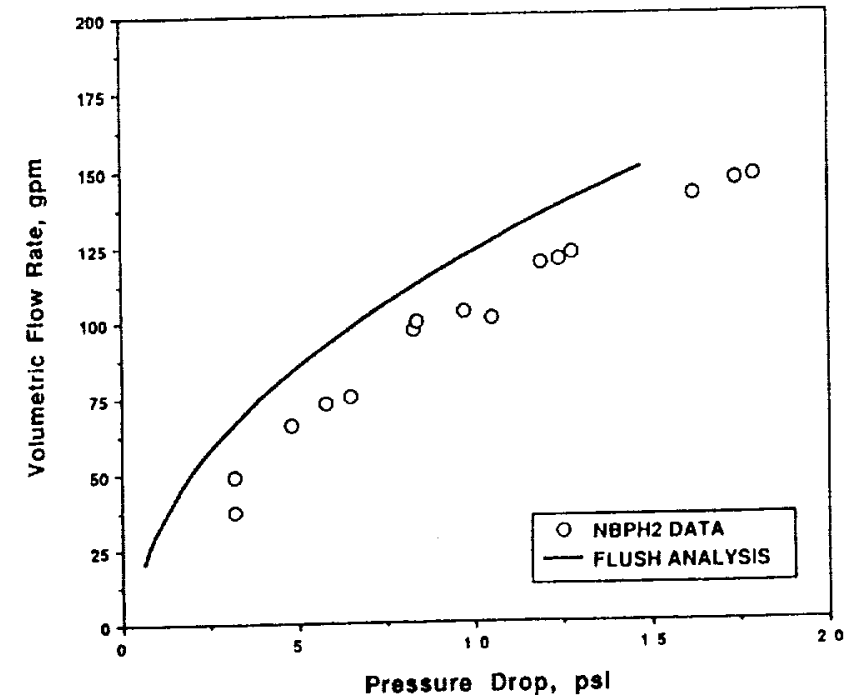

Figure 8.-Comparison of $\mathrm{NBPH}_{2}$ volumetric flow rate data with FLUSH analysis.

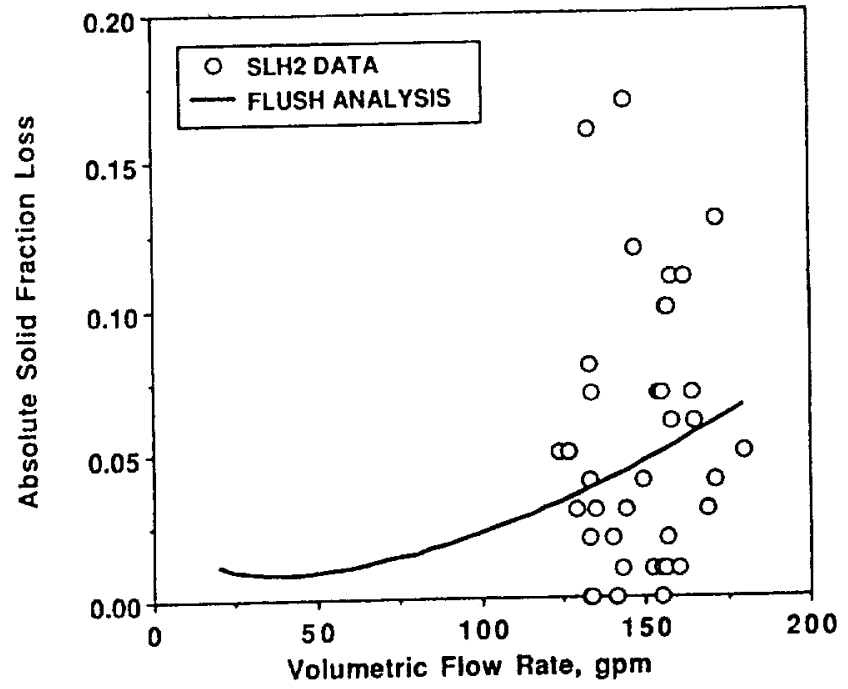

Figure 9.-Comparison of $\mathrm{SLH}_{2}$ solid fraction loss data with FLUSH analysis.

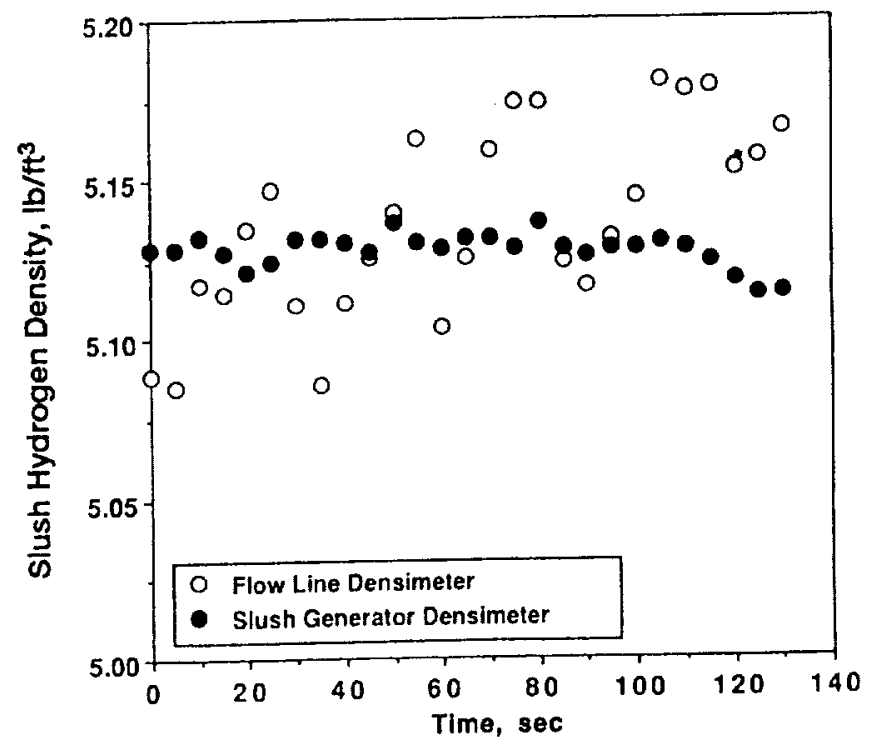

Flgure 10.-Slush hydrogen density during transfer: run no. 5464, RDG. 969 , flow rate $=144 \mathrm{gpm}$. 
Pulic reporting burden for this collection of information is estimated to average 1 hour per response, including the time for reviewing instructions, searching existing data sources, Public repotion of information. Send comments regarding this burden estimate or any other aspect of this collection of information, including suggestions for reducing this burden, to Washington Headquarters Services, Directorate for information Operations and Reports, 20503. collection of ination , Arlington, VA 22202-4302, and to the Otfice of Management and Budget, Paperwork Reduction Project (0704-0188), Washinglon, DC 20503.

\begin{tabular}{|l|r|r|}
\hline 1. AGENCY USE ONLY (Leave blank) & 2. REPORT DATE & 3. REPORT TYPE AND DATES COVERED \\
Technical Memotandum
\end{tabular}

\section{TITLE AND SUBTITLE}

Slush Hydrogen Transfer Studies at the NASA K-Site Test Facility

6. AUTHOR(S)

Terry L. Hardy and Margaret V. Whalen
WU-763-22-21

8. PERFORMING ORGANIZATION REPORT NUMBER

E-6932

National Aeronautics and Space Administration

Lewis Research Center

Cleveland, Ohio 44135-3191

SPONSORING/MONITORING AGENCY NAMES(S) AND ADDRESS(ES)

National Aeronautics and Space Administration

Washington, D.C. 20546-0001
10. SPONSORING/MONITORING AGENCY REPORT NUNBER

NASA TM -105596

AIAA-92-3384

\section{SUPPLEMENTARY NOTES}

Prepared for the 28th Joint Propulsion Conference and Exhibit cosponsored by AIAA, SAE, ASME, and ASEE, Nashville, Tennessee, July 6-8, 1992. Responsibie person, Terry L. Hardy, (216) 977-7517.

12a. DISTRIBUTION/AVAILABILITY STATEMENT

12b. DISTRIBUTION CODE

Unclassified - Unlimited

Subject Category 28

\section{ABSTRACT (Maximum 200 words)}

An experimental study was performed as part of the National Aero-Space Plane effort to determine slush hydrogen production and transfer characteristics. Flow rate and pressure drop characteristics were determined for slush hydrogen flow through a vacuum-jacketed transfer system. These characteristics were compared to similar tests using normal boiling point and triple point hydrogen. In addition, experimental flow characteristic data was compared with predictions from the FLUSH analytical model. Slush hydrogen density loss during the transfer process was also examined.

Hydrogen; Hydrogen fuels; Liquid hydrogen; Cryogenic fluids; Cryogenic fluid storage; Cryogenics; National Aero-Space Plane Program; Space exploration; Slush hydrogen
15. NUMBER OF PAGES

10

16. PRICE CODE

A03

\section{SECURITY CLASSIFICATION OF REPORT}

Unclassified
18. SECURITY CLASSIFICATION OF THIS PAGE Unclassified
19. SECURTY CLASSIFICATION OF ABSTRACT

Unclassified 